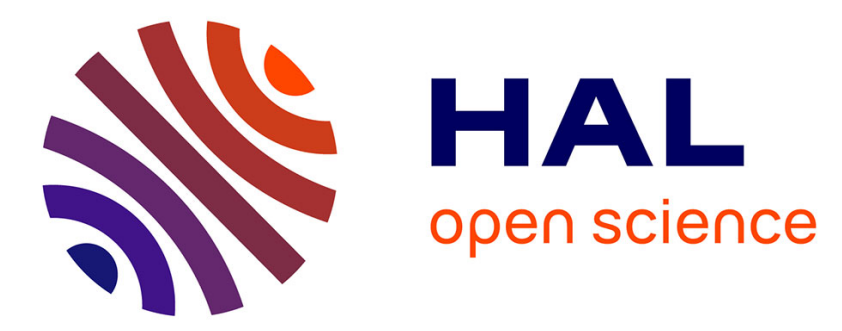

\title{
Laboratory characterization of firebrands involved in spot fires
}

Ganteaume, Guijarro, Jappiot, Hernando, Lampin-Maillet, Pérez-Gorostiaga, José Vega

\section{> To cite this version:}

Ganteaume, Guijarro, Jappiot, Hernando, Lampin-Maillet, et al.. Laboratory characterization of firebrands involved in spot fires. Annals of Forest Science, 2011, 68 (3), pp.531-541. 10.1007/s13595011-0056-4 . hal-00930791

\section{HAL Id: hal-00930791 https://hal.science/hal-00930791}

Submitted on 1 Jan 2011

HAL is a multi-disciplinary open access archive for the deposit and dissemination of scientific research documents, whether they are published or not. The documents may come from teaching and research institutions in France or abroad, or from public or private research centers.
L'archive ouverte pluridisciplinaire HAL, est destinée au dépôt et à la diffusion de documents scientifiques de niveau recherche, publiés ou non, émanant des établissements d'enseignement et de recherche français ou étrangers, des laboratoires publics ou privés. 


\title{
Laboratory characterization of firebrands involved in spot fires
}

\author{
Anne Ganteaume • Mercedes Guijarro • Marielle Jappiot • Carmen Hernando • \\ Corinne Lampin-Maillet • Pedro Pérez-Gorostiaga • José A. Vega
}

Received: 5 July 2010 / Accepted: 3 November 2010/Published online: 7 April 2011

(C) INRA and Springer Science+Business Media B.V. 2011

\begin{abstract}
- Introduction Wildfires are considered the most important disturbance in the Mediterranean Basin, and some are propagated over long distances due to lift-off and ignition of firebrands.

- Objectives To improve our knowledge of firebrands involved in spotting fires, flammability characteristics of eight types of firebrands commonly generated by wildfires in Southern Europe were determined under laboratory conditions.

- Results All the firebrands tested showed 100\% ignition frequency but with a wide range of time to ignition and flaming duration. Weight loss during combustion was exponentially related to time, and there was a decrease in the ratio of the weight at temperature $T$ to the initial weight with increasing temperatures. In our experimental conditions, there was a significant effect of fuel moisture content on time to ignition, flaming duration, combustion and thermal decomposition. On the basis of the characteristics analysed, three firebrand groups have been identified in
\end{abstract}

Handling Editor: David Hibbs

Electronic supplementary material The online version of this article (doi:10.1007/s13595-011-0056-4) contains supplementary material, which is available to authorized users.

A. Ganteaume $(\bowtie) \cdot$ M. Jappiot $\cdot$ C. Lampin-Maillet

Cemagref, UR EMAX,

3275 Route de Cézanne, CS 40061,

13182 Aix-en-Provence, France

e-mail: anne.ganteaume@cemagref.fr

M. Guijarro $\cdot$ C. Hernando

INIA, CIFOR,

28040 Madrid, Spain

P. Pérez-Gorostiaga · J. A. Vega

CIF Lourizán,

36153 Pontevedra, Spain relation to spotting: heavy firebrands with ability to sustain flames, efficient for long-distance spotting (pine cones); light firebrands with high surface-to-volume ratio, efficient for short-distance spotting (leaves and thin barks); and light firebrands with low surface-to-volume ratio, efficient for short and, occasionally, long-distance spotting (all the other types of firebands).

Keywords Firebrand · Fire behaviour - Flammability parameters $\cdot$ Wildfire $\cdot$ Ember

\section{Introduction}

In the Mediterranean Basin, wildfires alter thousands of hectares of forest and shrubland ecosystems (JRC 2009). Some of these wildfires are propagated over long distances due to the spotting mechanism. Spotting is frequently related to crown fires; it complicates wildland fire control and is one of the main causes of loss of homes in wildlandurban interface areas. Spotting is a fire propagation mechanism which spreads fire by producing firebrands that are carried up in the rising convection column and then drift and fall on remote sites. Despite its important role in fire spread, spotting has rarely been modelled. McArthur (1967) produced an empirical model that predicts mean spotting distance for Eucalyptus forests. Albini developed several mathematical models to predict potential spot fire distance from torching trees (Albini 1979), a burning pile (Albini 1981) and a wind-driven surface fire (Albini 1983). Gardner et al. (1999) reviewed the main fire models and showed that most simulations do not include the influence of firebrands on fire pattern. Hargrove et al. (2000) developed a fire model (EMBYR) incorporating the effects of fuel moisture and wind on fire ignition and spread, 
including the role of firebrands in the spread and spatial pattern of crown fires.

Spotting comprises three phases: (a) the generation of firebrands from burning vegetation and structures, (b) their subsequent transport through the atmosphere by external and heat generated winds, and (c) potential spot fire ignition after the firebrand has landed. Production of firebrands from burning vegetation has rarely been studied (but see Manzello et al. 2007, 2008), whereas transport of embers has received more attention (e.g. Tarifa et al. 1967; Albini 1983; Woycheese et al. 1999; Himoto and Tanaka 2005; Anthenien et al. 2006). Research to quantify the transport of firebrands made of burning vegetation has mainly concentrated on spherical and cylindrical firebrands. Some experimental studies have also been conducted on the ignition of fuel beds due to firebrand impact (e.g. Waterman and Takata 1969; Ellis 2000; Pérez-Gorostiaga et al. 2002; Manzello et al. 2006a, 2006b; Ganteaume et al. 2009), but little empirical data are available on firebrands and their burning characteristics.

Firebrands lofted into the atmosphere may be carried by winds over long distances (up to several kilometres). So, knowledge of their physical characteristics is useful for improving models that deal with firebrand trajectories. Hot firebrands with a significantly long burn-out time can land on fuel sources far removed from the initial fire, resulting in spot fire ignition and increased rates of spread (Manzello et al. 2007). Thus, firebrand flammability characteristics such as ignitability (assessed by time to ignition or ignition frequency), sustainability (assessed by the duration of flames), combustibility (assessed by gross heat combustion) or thermal decomposition have been studied because of their importance in quantifying firebrand efficiency in the ignition of spot fires. Digital simulations of weight loss by the firebrands as a function of time (combustion) and of temperature (thermal decomposition) will be useful to assess the temperatures involved in the decomposition of the vegetation and to analyse variations between plant species that generate firebrands.

The aim of the present study was to assess the efficiency of firebrands commonly encountered in forest ecosystems of Southern Europe to ignite spot fires based on physical and flammability characteristics. This study was part of the experimental work conducted in the SALTUS Project, a more comprehensive research project on the mechanisms involved in spot fires (SALTUS 2001). It was based on the assumption that the selected firebrands are amongst those most commonly involved in spot fires in the study regions.

\section{Materials and methods}

Experiments on firebrand characteristics were carried out under laboratory conditions by three research teams (INIA and CIF in Spain; Cemagref in France). The three teams used similar methodologies for testing the most common species from each study region: Central and North-western Spain and Southern France (Quézel and Médail 2003).

\subsection{Types and physical characteristics of firebrands}

Eight kinds of firebrands from different parts of trees and of various shapes were studied: pine twigs (Pinus halepensis and Pinus pinea), pine bark plates (P. halepensis, Pinus pinaster, $P$. pinea and Pinus radiata), Eucalyptus bark (Eucalyptus globulus), leaves (E. globulus and Quercus ilex), pine cone scales ( $P$. halepensis, $P$. pinaster and $P$. pinea), pine cones (P. halepensis), acorns $(Q$. ilex) and bark cubes (Quercus suber).

Because particle geometry is an important factor in determining the transport and combustion of firebrands (Anthenien et al. 2006), their dimensions (in centimetres) and weights were measured. Dimensions were measured using a $10^{-4}-\mathrm{m}$ accuracy micrometre. For pine twigs and cone scales, only thickness was measured. For the bark samples, a rectangular shape $(2 \times 3$ to $5 \mathrm{~cm})$ was chosen, but small cubes (roughly $1 \mathrm{~cm}^{3}$ ) were cut in the $Q$. suber bark. To characterize the leaf surface exposed to hot gases and fire during combustion, leaf width and length were measured along the central vein (without taking the petiole into account) and leaf thickness was measured avoiding thick veins. To obtain relatively stable weight data, the samples were ovendried at $60^{\circ} \mathrm{C}$ for $24 \mathrm{~h}$. For all the firebrands, depending on their shape (cylindrical, rectangular or spherical), the surface of contact (in square centimetres) with the fuel bed, the total surface (in square centimetres), the volume (in cubic centimetres) and the total surface-to-volume ratio were calculated using geometrical formulae.

\subsection{Ignition frequency, time to ignition and duration of flames}

We assessed flammability of the firebrands using an experimental device partially based on the "flammability measurement method" (Delabraze and Valette 1974) used by other authors (Valette 1988; Hernando et al. 1994). The device consists of a $500-\mathrm{W}$ electric radiator with a $10-\mathrm{cm}$ diameter radiant disk; the surface temperature was $420^{\circ} \mathrm{C}$ at steady-state regime. After weighing and measuring, each firebrand was exposed to the heat source. Firebrands longer than the electric radiator were trimmed to fit it. Firebrand samples were in direct contact with the electric radiator, the surface of contact depended on their type (see Table 1). The surface touching the radiator was assumed to be close enough to the heat source to undergo heat transfer effects in a homogeneous way. Once samples were placed on the electric radiator, the time to ignition (TTI) and flame 


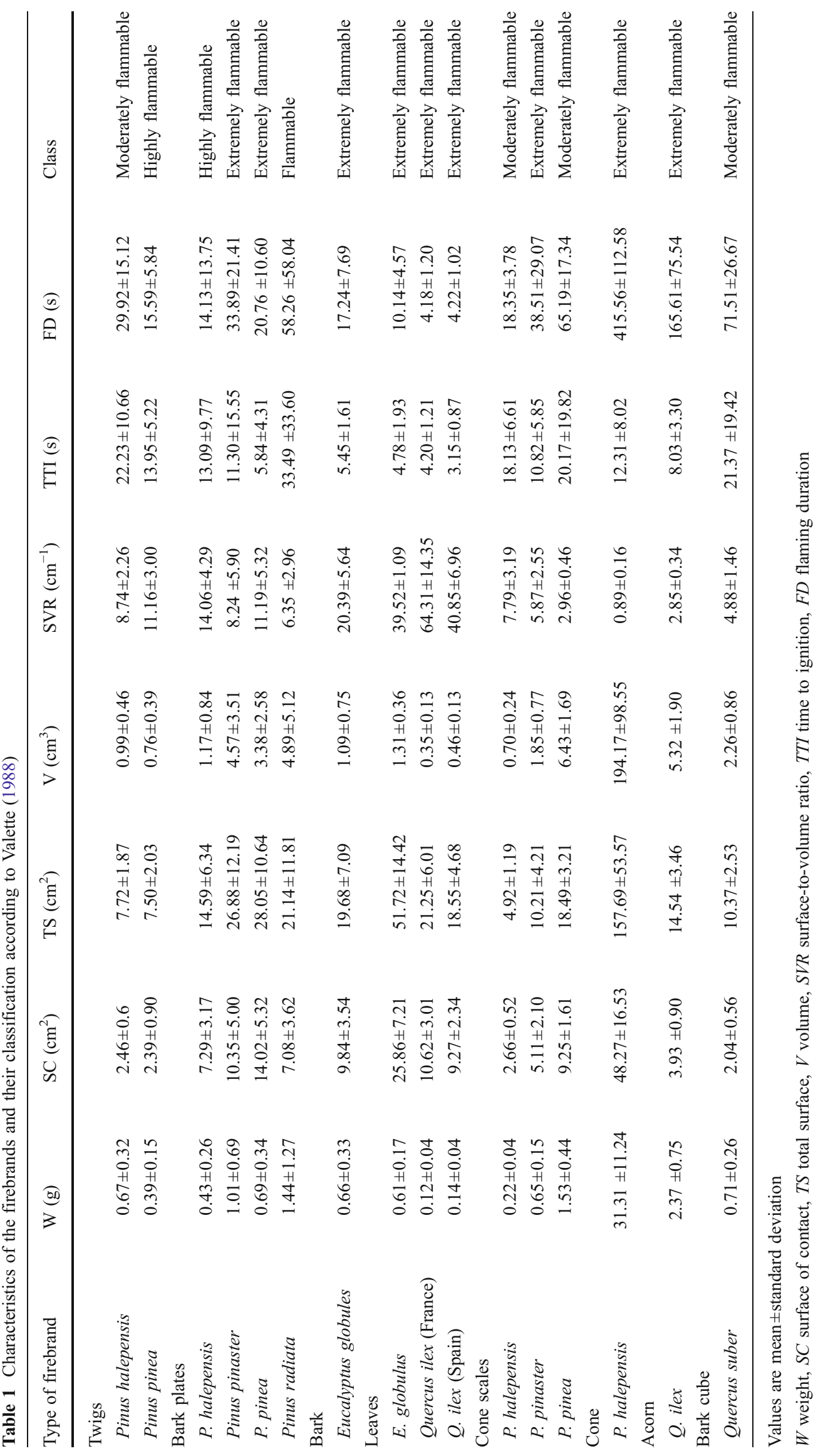


extinction (enabling the calculation of the flaming duration (FD) of the firebrand) were recorded for each firebrand. The ignition frequency of the firebrand was calculated as the percentage of tests in which firebrands ignited. Each firebrand was classified according to its ignition frequency and its mean time to ignition following Valette's classification (Valette 1988): $0=$ very difficult to ignite; $1=$ difficult to ignite; 2 =flammable; $3=$ moderately flammable; $4=$ highly flammable; and $5=$ extremely flammable. It should be noted that the above classification was established for tests performed with a heat source and a pilot flame while in the present study, no pilot flame was used. We nevertheless selected this classification because it enabled us to compare different firebrands.

\subsection{Loss of weight with time}

The experimental device was the same electric radiator described above, but included simultaneously monitoring weight loss of the firebrands during combustion, measured at $1 \mathrm{~s}$ intervals. This test was only conducted on $P$. halepensis bark plates, $P$. halepensis cone scales and $Q$. suber bark cubes as the flaming combustion of needles and leaves was too rapid and the weight was too low to be monitored in the selected timeframe. For each firebrand, two levels of fuel moisture content (FMC) were selected: air-dried samples and oven-dried samples (dried at $60^{\circ} \mathrm{C}$ for $24 \mathrm{~h}$ ).

For each firebrand and each FMC, 50 samples were tested and the following parameters were measured: TTI (time elapsed from the moment the firebrand was placed on the radiator to the moment of ignition), FD (time during which combustion of the firebrand continued with visible flame), combustion duration (CD; time during which combustion of the firebrand continued without flame, i.e. the glowing time of the firebrand), initial weight before ignition (M1), weight after combustion with flame (M2), weight after combustion without flame (M3) and weight losses (M1-M2)/M1 and (M1-M3)/M1.

\subsection{Loss of weight depending on temperature}

To study thermal decomposition, weight loss had to be analysed as a function of temperature. The furnace used in the experiment heated to $1,100^{\circ} \mathrm{K}$. Thermal decomposition was measured on eight firebrands: needles of Pinus eldarica, $P$. halepensis, $P$. pinaster and $P$. pinea; twigs of $P$. halepensis; bark plates of $P$. halepensis; cone scales of $P$. halepensis; and bark cubes of $Q$. suber.

First, each sample was oven-dried at $60^{\circ} \mathrm{C}$ for $24 \mathrm{~h}$, then weighed with a precision of $0.001 \mathrm{~g}$ (initial weight of $5 \mathrm{~g}$ ). Five samples for each temperature were analysed without opening the furnace, i.e. without a supply of oxygen. Temperatures ranged from $373.15^{\circ} \mathrm{K}$ to $973.15^{\circ} \mathrm{K}$, at $50^{\circ} \mathrm{K}$ increments. Changes in the MT/MI ratio (weight at temperature $\mathrm{T}$ /initial weight), which is a function of temperature where MT is the weight (milligrammes) at temperature $\mathrm{T}\left({ }^{\circ} \mathrm{K}\right)$ and $\mathrm{MI}$ is the initial weight (milligrammes), were analysed.

\subsection{Gross heat of combustion}

To estimate the gross heat of combustion of the firebrands, we used standard methods (Spanish Standard UNE 2310378 and International Standard ISO 1716 of 1973). All fuel samples were ground individually to $5.10^{-4} \mathrm{~m}$ in a mill. From the ground material, pellets of about $1 \mathrm{~g}$ were prepared using a hand press, oven-dried at $100 \pm 5^{\circ} \mathrm{C}$ for $24 \mathrm{~h}$ and then weighed. Measurements were made with an adiabatic bomb calorimeter with a platinum resistance sensor (PT-100). Both mill and bomb calorimeter were manufactured by IKA $^{\circledR}$ and were located in the Forest Fire Laboratory of INIA-CIFOR, Spain. For each type of firebrand, the same measurements were made on two samples. A third sample was included whenever the difference between the first two values was more than $2 \%$ of the mean value.

According to the classification proposed by Elvira and Hernando (1989), one class of forest fuel corresponds to each gross heat of combustion (GHC) measured: medium: $18,810 \mathrm{~kJ} \mathrm{~kg}^{-1}<\mathrm{GHC}<20,900 \mathrm{~kJ} \mathrm{~kg}^{-1}$, high: $20,900 \mathrm{~kJ} \mathrm{~kg}^{-1}<\mathrm{GHC}<22,990 \mathrm{~kJ} \mathrm{~kg}^{-1}$ and very high: $22,990 \mathrm{~kJ} \mathrm{~kg}^{-1}<\mathrm{GHC}$.

\subsection{Data analysis}

As according to the Kolmogorov-Smirnov test, the data distributions were not normal, so a one-factor nonparametric analysis of variance (ANOVA; Kruskal-Wallis test) was used to test the significance of the relationship between the type of firebrands (predictor variable) and the response variables TTI, FD and MT/MI. In the combustion experiment, the distributions were not normal (Kolmogorov-Smirnov test), so means were compared using the Mann-Whitney non-parametric test, which tests the significance of the effects of the predictor variables "moisture content" and "firebrand type" on the response variables TTI, FD, CD, (M1-M2)/M1 and (M1-M3)/M1. As the gross heat of combustion experiments were carried out on two or three samples of each type of firebrand, a oneway non-parametric ANOVA (Kruskal-Wallis test) was used to validate the significance of the relationship between 'type of firebrand' (predictor variables) and 'gross heat of combustion' (response variable). A significant relationship between the variables was assumed when the probability was less than 0.05 . The number of replicates of each test is shown in Tables SI and SII, available at www.afs-journal.org. Non- 
linear regression analysis (exponential model) was used to show the correlation between temperature and the ratio MT/ MI during thermal decomposition of different firebrands. The firebrand thermal decomposition can be modelled using a non-linear statistical analysis of the following equation:

$y=\exp ^{\left(a+b^{*} x\right)}=\exp ^{(a) * \exp ^{\left(-b^{*} x\right)}}$

where

$y$ mean proportion of weight remaining (MT/MI)

$x$ temperature

$a$ intercept

$b$ thermal decomposition loss rate.

Finally, to identify groups of particles or species with common characteristics in relation to spotting, a hierarchical cluster analysis was carried out by using Ward's method (Johnson and Wichern 1982). All analyses were performed using Statgraphics Centurion XV.

\section{Results}

\subsection{Physical characteristics of firebrands}

Mean and standard deviation of weight, surface of contact, total surface, volume and surface-to-volume ratio of the firebrands are presented in Table 1. Range is listed in Table SI, available at www.afs-journal.org. The cones of $P$. halepensis were the heaviest firebrands $(31.31 \mathrm{~g})$ used in the experiment and bark cubes of $Q$. suber were amongst the bulkiest $(L=1.5 \mathrm{~cm} ; w=1.3 \mathrm{~cm} ; t=1.1 \mathrm{~cm})$. The firebrand with the smallest surface area to volume ratio was $P$. halepensis cone $\left(0.88 \mathrm{~cm}^{-1}\right)$; indeed, it presented the highest surface of contact $\left(48.27 \mathrm{~cm}^{2}\right)$ and volume $\left(194.17 \mathrm{~cm}^{3}\right)$. Results revealed high variability within each type of firebrand (see Table SI), but given the large number of samples $(n>200)$, this variability may be due to ecological and physiological mechanisms.

\subsection{Ignition frequency, time to ignition and flaming duration}

All the firebrands showed $100 \%$ ignition frequency. Results of time to ignition and flaming duration (mean and standard deviation) of the firebrands are shown in Table 1. Range is presented in Table SI, available at www.afs-journal.org. Both TTI and FD showed a wide range of variability. The type of firebrand had a significant effect on TTI and FD, and this effect was independent of the part of the tree or the species from which the sample was taken (Kruskal-Wallis test: $\mathrm{KW}>100$ and $p<0.0001)$. Q. ilex leaves presented the shortest time to ignition and the shortest flaming duration. $P$. radiata bark plates had the longest TTI and $P$. halepensis cones the longest FD (Table 1).

\subsection{Loss of weight with time}

Firstly, it should be noted that temperatures reached in combustion tests were much lower than those observed in wildfires, but nevertheless enabled us to record the flammability parameters particular to each firebrand. Indeed, as fires are heterogeneous, sustained temperatures are rarely observed and can vary significantly over small spatial scales. In addition, if the particles land on fuels, lags in ignition will be important in determining fire behaviour.

The values recorded during combustion are presented in Table 2 and Table SII (available at www.afs-journal.org). The air-dried Quercus suber bark underwent the greatest weight losses (M1-M2)/M1 (0.86) and (M1-M3)/M1 (0.90). The oven-dried $P$. halepensis bark underwent the smallest weight loss after flaming combustion (M1-M2)/ M1 (0.72) and the oven-dried P. halepensis cone scales underwent the smallest weight loss after glowing combustion (M1-M3)/M1 (0.83). It was not possible to record the weight loss of $Q$. ilex leaves as the initial weight of this firebrand was too light. Air-dried P. halepensis cone scales and bark presented the longest time to ignition $(19.49 \mathrm{~s}$ and $16.76 \mathrm{~s})$. The most ignitable firebrands were $Q$. ilex leaves (regardless of the FMC). Q. suber bark presented the longest flaming and combustion durations and $Q$. ilex leaves the shortest.

\subsubsection{The effect of fuel moisture content}

Regarding time to ignition, the effect of FMC was significant in all the firebrands tested (Mann-Whitney test: $U>2.5$ and $p<0.01$ ). With the exception of $Q$. suber bark (Fig. 1), time to ignition decreased with decreasing FMC. Regarding flaming duration, moisture content was significant only in $P$. halepensis bark, $Q$. suber bark and Q. ilex leaves (MannWhitney test: $U>2.2$ and $p<0.05$ ), flaming duration decreased with a decrease in FMC. An increase in fuel moisture resulted in an increase in flaming duration except in P. halepensis cone scales and needles (Fig. 1). Regarding combustion duration, only $Q$. suber bark and Q. ilex leaves showed a significant decrease in combustion duration at the lowest FMC values (Mann-Whitney test: $U>4$ and $p<0.0001$ ).

Regarding weight loss following flaming combustion, FMC had a significant effect on all the firebrands (MannWhitney test: $U>2$ and $p<0.05$ ). Regarding weight loss following glowing combustion, the effect was not significant in $Q$. suber bark cubes (Mann-Whitney test: $U=1.55$ and $p=0.12$ ). 


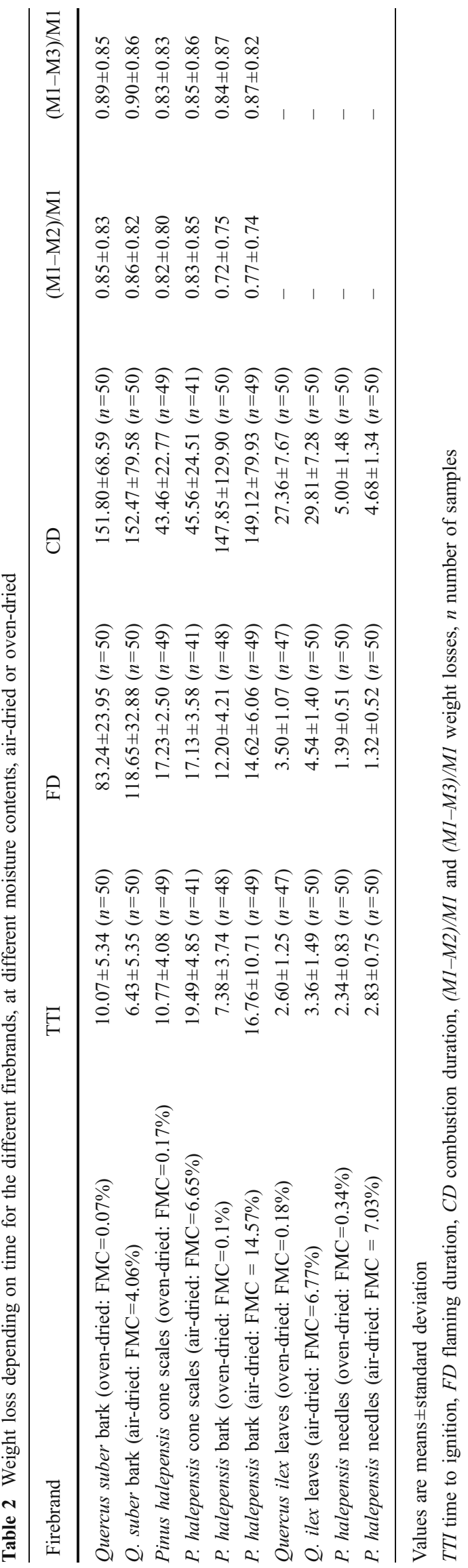

\subsubsection{The effect of the type of firebrand}

In the case of air-dried firebrands, time to ignition differed significantly (Mann-Whitney test: $U>2.23$ and $p<0.05$ ) except between $P$. halepensis bark and $P$. halepensis cone scales (Mann-Whitney test: $U=1.58$ and $p=0.11$ ). For oven-dried firebrands, time to ignition differed significantly only between $Q$. ilex leaves and $P$. halepensis bark and between $P$. halepensis bark and $Q$. suber bark (MannWhitney test: $U>3.8$ and $p \leq 0.0001$ ).

Regardless of the FMC, the flaming duration differed significantly among the firebrands tested (Mann-Whitney test: $U>2.4$ and $p<0.05$ ).

The combustion duration differed significantly regardless of the FMC (Mann-Whitney test: $U>3.9$ and $p<$ 0.0001) except between $P$. halepensis bark and cone scales and between $P$. halepensis bark and $Q$. suber bark.

Regarding weight loss following flaming combustion, values differed significantly regardless of the FMC (MannWhitney test: $U>8.2$ and $p<0.0001$ ).

Regarding weight loss following glowing combustion, the values of the air-dried firebrands differed significantly (Mann-Whitney test: $U>2.18$ and $p<0.05$ ). Regarding oven-dried firebrands, the values of $Q$. suber bark differed significantly from the other firebrands (Mann-Whitney test: $U=16.72$ and $p<0.0001$ ).

The ranking orders of the different firebrands for both FMCs are presented in Fig. 1.

\subsection{Loss of weight depending on temperature}

For each type of firebrand, changes in the MT/MI ratio (\%) are presented in Fig. 2. There was a decrease in the MT/MI ratio with an increase in temperature. The greatest weight loss occurred in $Q$. suber bark (MT/MI varying from $98.66 \%$ to $1.63 \%$ ) and $P$. halepensis cone scales (from $97.69 \%$ to $0.54 \%$ ). The type of firebrand did not have a significant effect on thermal decomposition (Kruskal-Wallis test: KW= 5.39, $p=0.61)$. Moreover, firebrands such as needles of different Pinus species displayed similar behaviour in their thermal decomposition. P. pinea had the lowest MT/MI ratio $(2.23 \%)$ at the highest temperature $\left(973^{\circ} \mathrm{K}\right)$. This ratio was the highest amongst the pine needles when the temperature was the lowest $\left(373^{\circ} \mathrm{K}\right)$. P. pinea underwent faster thermal decomposition than the other species. Variations were observed between different firebrands such as P. halepensis twigs, bark or bark plates. Cone scales underwent the fastest thermal decomposition, and needles the slowest (Fig. 2).

Non-linear regression analyses revealed that there was a strong negative relationship between temperature and weight loss (\% MT/MI) for all the firebrands (Fig. 2). $P$. elderica needles presented the highest correlation (correlation coefficient $=-0.989$ ) and $P$. halepensis cone scales the 
口Oven-dried $\square$ Air-dried Order of ranking : 1 to 4

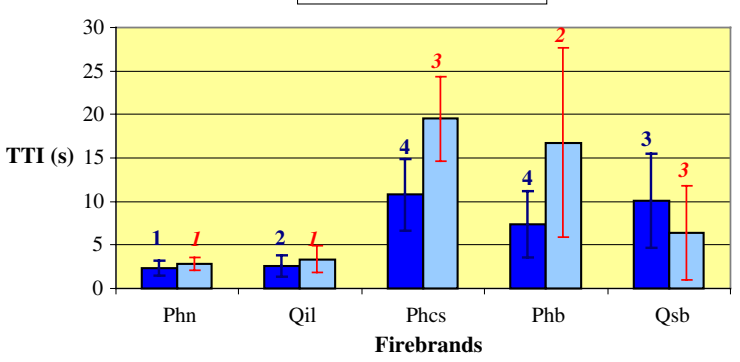

Oven-dried $\square$ Air-dried

Order of ranking : 1 to 5

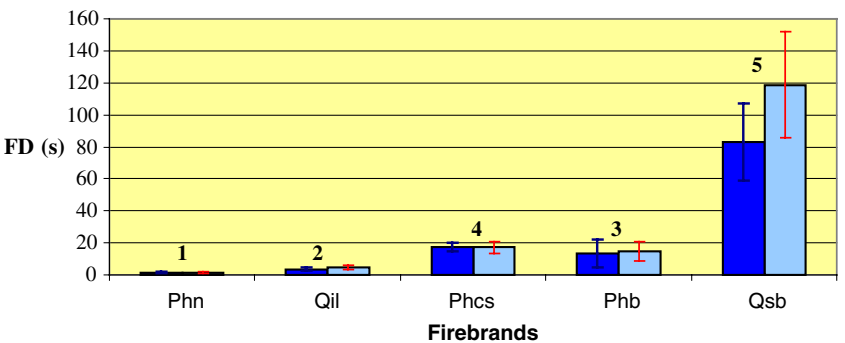

$\square$ Oven-dried $\square$ Air-dried

Order of ranking : 1 to 4

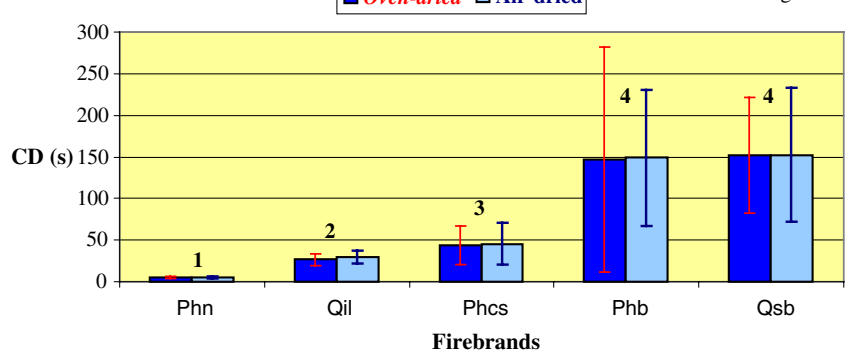

Fig. 1 Time to ignition, flaming duration, combustion duration, weight loss following flaming combustion and weight loss following glowing combustion according to the type and moisture content of firebrand ( $P h n$ Pinus halepensis needles, Qil Quercus ilex leaves, P. halepensis cone

lowest correlation (correlation coefficient $=-0.956$ ) (see equations that give the loss of the weight $(y)$ depending on temperature $(x)$ for each type of firebrand, in Table SIII, available at www.afs-journal.org).

\subsection{Gross heat of combustion}

The gross heat of combustion of each type of firebrand (average of two or three samples) as well as the class of forest fuel is presented in Table 3. The type of firebrand had a significant effect on gross heat of combustion (GHC; $\mathrm{KW}=37.15, p=0.0007)$ and the bark cubes of $Q$. suber had the highest value $\left(\mathrm{GHC}=27613 \mathrm{~kJ} \mathrm{~kg}^{-1}\right)$. When only bark and cone scale were tested, the plant species had a significant effect on $\mathrm{GHC}(\mathrm{KW}=10.58, p=0.032$, maximum $\mathrm{GHC}$ for $P$. radiata and $\mathrm{KW}=6.25, p=0.044$, maximum GHC for $P$. halepensis). Plant species and geographical origin of $Q$. ilex leaves had a significant effect on $\mathrm{GHC}(\mathrm{KW}=6.25, p=0.044$, maximum $\mathrm{GHC}$ for
Oven-dried $\square$ Air-dried Order of ranking : 1 to 3
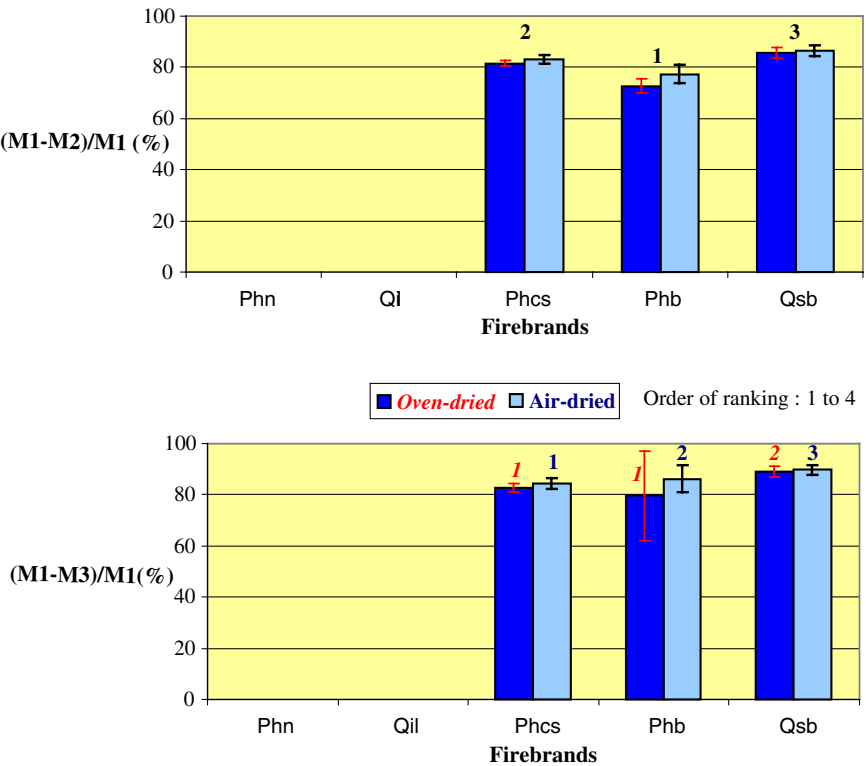

scales, Phb P. halepensis bark, Phcs pinus 17 halepensis cone scales, Qsb Quercus suber bark, TTI time to ignition, FD, flaming duration, $C D$ Combustion duration, $(M 1-M 2) / M 1$ weight loss following flaming combustion, (M1-M3)/M1 weight loss following glowing combustion)

E. globulus leaves). The GHC of Q. ilex leaves from Spain and France differed significantly (Table 3 ).

\subsection{Cluster analysis}

The hierarchical cluster analysis based on the values of the physical characteristics of firebrands, and their time to ignition and flaming duration identified three groups (see Fig. S1, available at www.afs-journal.org): (1) P. halepensis cone, (2) leaves of E. globulus and Q. ilex and bark of $E$. globules and (3) all the other types of firebrands.

\section{Discussion}

The burning characteristics of the different types of firebrands tested in this study address important aspects of their flammability and hence their capability to ignite spot fires (Ganteaume et al. 2009). Physical characteristics such 

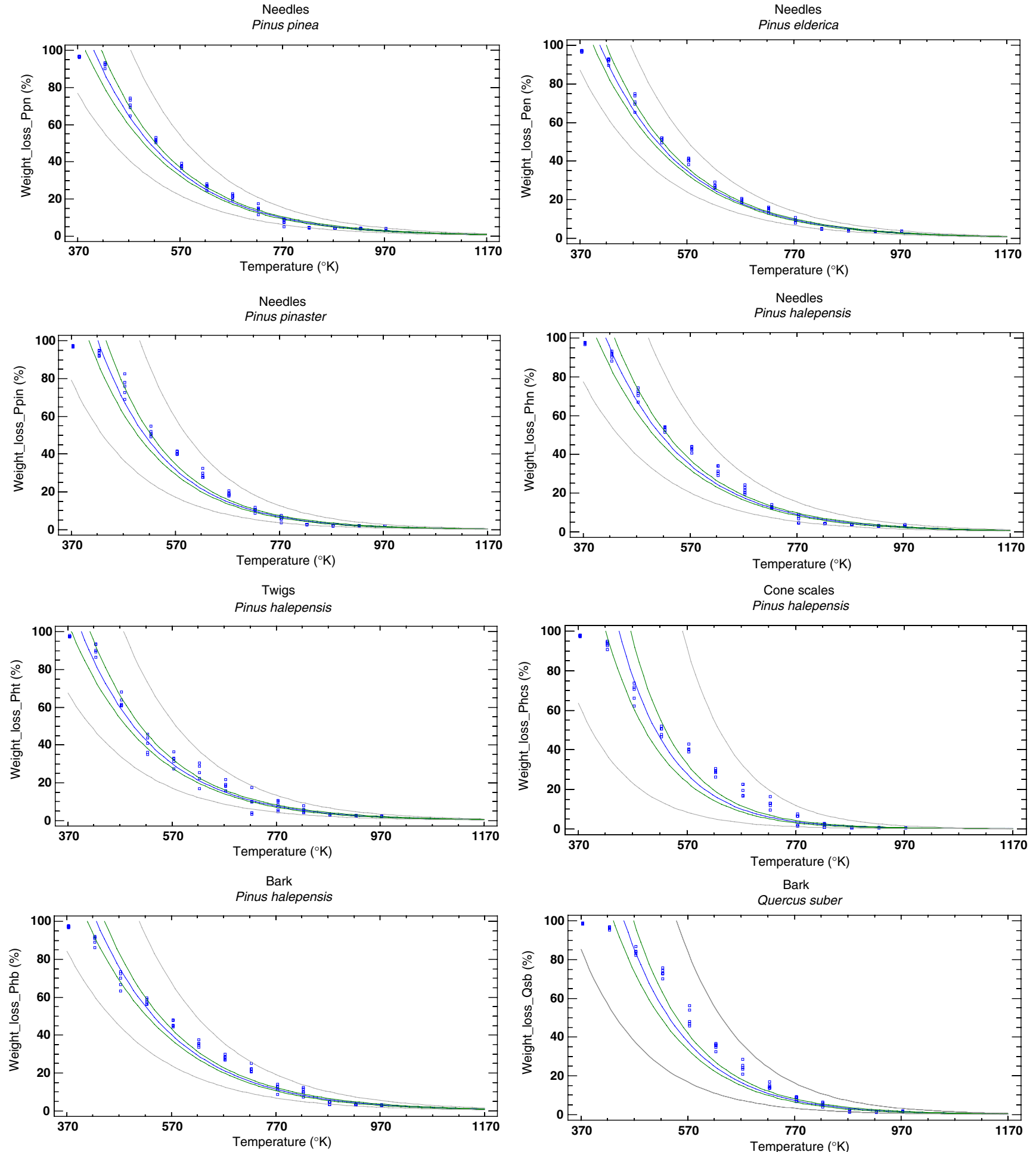

Fig. 2 Non-linear regression of weight loss (\%MT/MI) of different species of firebrands as a function of temperature (Ppn Pinus pinea needles, Pen Pinus eldarica needles, Ppin Pinus pinaster needles, Phn

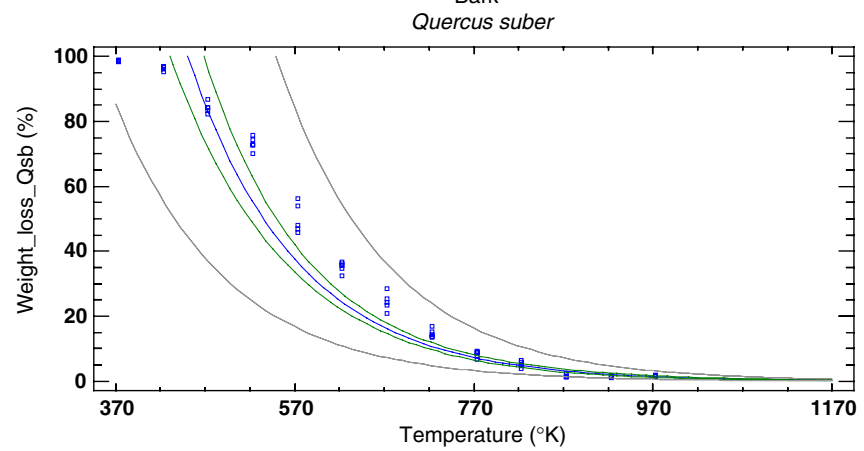

Pinus halepensis needles, Pht P. halepensis twigs, Phcs P. halepensis cone scales, Phb P. halepensis bark, Qsb Quercus suber bark

Of all the firebrands, $P$. halepensis cones were the as firebrand weight, surface-to-volume ratio or surface contact revealed differences in the flammability characteristics of these firebrands.

heaviest and had the lowest surface-to-volume ratio. These characteristics may explain flammability parameters such as 
Table 3 Gross heat of combustion of firebrands (average of two or three samples and standard deviation) and forest fuel class

\begin{tabular}{|c|c|c|}
\hline Type of firebrand & $\begin{array}{l}\text { Gross heat of } \\
\text { combustion }\left(\mathrm{kJ} \mathrm{kg}^{-1}\right)\end{array}$ & Class \\
\hline \multicolumn{3}{|l|}{ Needles } \\
\hline Pinus halepensis & 22,940 & High \\
\hline \multicolumn{3}{|l|}{ Twig } \\
\hline Pinus pinea & $20,183(98.91)$ & Medium \\
\hline \multicolumn{3}{|l|}{ Bark plates } \\
\hline P. halepensis & $19,469(35.76)$ & Medium \\
\hline Pinus pinaster & $20,548(94.56)$ & Medium \\
\hline P. pinea & $20,040(8.80)$ & Medium \\
\hline Pinus radiata & $21,583(17.96)$ & High \\
\hline \multicolumn{3}{|l|}{ Bark } \\
\hline Eucalyptus globulus & $18,870(118.4)$ & Medium \\
\hline \multicolumn{3}{|l|}{ Leaves } \\
\hline E. globulus & $22,665(44.4)$ & High \\
\hline Quercus ilex (France) & $20,690(105.09)$ & Medium \\
\hline Q. ilex (Spain) & $19,345(135.34)$ & Medium \\
\hline \multicolumn{3}{|l|}{ Cone scales } \\
\hline P. halepensis & $20,962(106.91)$ & High \\
\hline$P$. pinaster & $20,537(29.60)$ & Medium \\
\hline$P$. pinea & $20,153(285.95)$ & Medium \\
\hline \multicolumn{3}{|l|}{ Cone } \\
\hline P. halepensis & $20,650(63.34)$ & Medium \\
\hline \multicolumn{3}{|l|}{ Acorn } \\
\hline Q. ilex & 19,067 (118.40) & Medium \\
\hline \multicolumn{3}{|l|}{ Bark cube } \\
\hline Quercus suber & $27,654(262.90)$ & Very high \\
\hline
\end{tabular}

$n=2$ or 3

their long flaming duration compared with the other firebrands. The average flaming duration of this type of firebrand ( $415 \mathrm{~s}$ ) is within the range (207 to $740 \mathrm{~s}$ ) recorded for burning characteristics of cones from eight American pine species (Fonda and Varner 2004). Because of their ability to sustain flames, $P$. halepensis cones were thought to be one of the most efficient firebrands in a spotting fire. This was confirmed in laboratory tests (Ganteaume et al. 2009). However, a field study (SALTUS 2001) showed that conifer cones are not a very common firebrand. Conversely, in our study, $Q$. ilex leaves were the lightest firebrands with a high surface-to-volume ratio and burned the most rapidly. Generally speaking, in our experiments, regardless of their FMC, needles and leaves burned most rapidly but for the shortest time because of their low weight and high surfaceto-volume ratio. Because of their short time to ignition, these firebrands were the most ignitable, the thinnest leaves being the most ignitable (Montgomery and Cheo 1971). According to Alessio et al. (2008), the ignitability of Q. ilex leaves and $P$. halepensis needles was of the same order. These firebrands did not sustain flames (very short flaming and combustion durations) and even if they had a high gross heat of combustion, they were too rapidly consumed to be efficient firebrands for long-distance fire spotting. Kane et al. (2008), analysing the burning characteristics of oak leaves from southeastern USA, found flaming durations ranging from 50.4 to $91.4 \mathrm{~s}$ and combustion durations ranging from 216 to $399.8 \mathrm{~s}$. These values are much higher than those we found for $Q$. ilex leaves in our study, mainly because the burning methods used in the two studied were different. Kane et al. (2008) followed the method outlined in Fonda et al. (1998) and Fonda (2001) and burned samples of litter bed (15 g of oven-dried leaves) in a $35 \times$ $35-\mathrm{cm}$ grid formed by eight xylene-soaked cotton strings, whereas in our experiment, only one leaf per trial was burned on an electric radiator. In our study, P. halepensis needles had short flaming and combustion durations (at the most 1.39 and $5 \mathrm{~s}$ ) due to the direct contact of the needle on the electric radiator whereas Fonda (2001) found much longer durations for eight American pine species (respectively, 63.5 to $195.4 \mathrm{~s}$ and 69.9 to $360.1 \mathrm{~s}$ ) certainly due to the increased packing ratio of the needles. This difference in flaming durations was, indeed, mainly due to the abovementioned difference in experimental methods. In Mutch's (1970) study of the burning duration of $P$. ponderosa needles, in which the author found an intermediate value (16.7 s), a different experimental method was also used. In his work, Mutch conducted laboratory combustion tests on $45.4 \mathrm{~g}$ fuel samples placed in wire mesh baskets and ignited by xylenedipped string. In our study, using an epiradiator, the time to ignition of $P$. halepensis needles was very short (less than 3 s). This result was also highlighted by Ormeño et al. (2009), who also used an electric radiator as burning device.

Even with a bad ignitability but with a good sustainability, $Q$. suber bark cubes underwent the greatest weight loss with time at both fuel moisture contents (air-dried and oven-dried). Consequently, this firebrand would not be very efficient in igniting a spot fire over long distances. Conversely, $P$. halepensis bark had the lowest weight losses with time, with a short flaming duration but very long combustion duration. Regarding thermal decomposition, $P$. halepensis bark was also the most efficient firebrand amongst the species studied; its ability to sustain combustion would enable it to be effective even after being lofted over greater distances. In our experimental conditions, most of the thermal decomposition followed a charring combustion pathway that would not occur in these fuels in natural conditions.

As can be seen in Table 3, only Q. suber bark presented a very high gross heat of combustion; this characteristic should favour its efficiency as a firebrand. P. halepensis needles and cone scales, P. radiata bark and E. globulus leaves showed a high gross heat of combustion, whereas 
that of the other firebrands was medium. The high GHC recorded with $P$. halepensis needles could be attributed to its higher production of essential oils and resins (Liodakis and Kakardakis 2006). Núñez-Regueira et al. (1996) predicted the risk of wildfire for different geographical zones in Galicia (NW Spain) using the different heat of combustion values of different species over a year. The values we obtained with E. globulus bark as well as with the bark plate and cone scale of $P$. pinaster are in the range of the values measured by these authors over a period of a year $(17,539$ to $20,760 \mathrm{~kJ} \mathrm{~kg}^{-1}$ and 19,481 to $20,659 \mathrm{~kJ} \mathrm{~kg}^{-1}$ ). However, E. globulus leaves presented higher GHC $\left(22,665 \mathrm{~kJ} \mathrm{~kg}^{-1}\right)$ than the values obtained by the previous authors. Using ground samples of needles collected during the dry season, Liodakis and Kakardakis (2006) found a lower GHC for $P$. halepensis than the value obtained in our experiments $\left(20,841\right.$ versus $\left.22,940 \mathrm{~kJ} \mathrm{~kg}^{-1}\right)$.

On the basis of these results and of the cluster analysis (Fig. S1), three firebrand groups could be distinguished in relation to spotting:

1. Heavy firebrands with ability to sustain flames. This type of firebrands is more difficult to transport through the atmosphere, but they have a high potential to ignite spot fires after they have landed. Therefore, they would be efficient firebrands for long-distance spotting. Pine cones, as $P$. halepensis ones, are included in this group.

2. Light firebrands with high surface-to-volume ratio and low ability to sustain flames. This type of firebrands is easy to transport in the second phase of spotting, but they are rapidly consumed. So they would only be efficient for short-distance spotting. This group comprises leaves and thin barks (e.g. E. globulus and Q. ilex leaves and E. globulus bark). It must be noticed that Eucalyptus bark is classically considered to be an effective firebrand (Pyne et al. 1996), because it is easily lifted from the trees and the curled shapes gives it aerodynamic features that allow it to be carried out for long distance. But in our study, this aerodynamic characteristic has not been analysed.

3. Light firebrands with low surface-to-volume ratio and higher ability to sustain flames. This type of firebrands has intermediate characteristics between groups 1 and 2, but they are closer to group 2 . They would be efficient for short and, occasionally, long-distance spotting. All the other types of firebrands, different from the pine cones, leaves and thin barks, are included in this group.

\section{Conclusions}

To improve our knowledge of firebrands involved in fire spotting, physical (weight, surface of contact, total surface, volume and surface-to-volume ratio) and flammability characteristics (ignition frequency, time to ignition, flaming duration, combustion, thermal decomposition and gross heat of combustion) of several types of firebrands commonly encountered in Southern Europe were determined in laboratory conditions. The firebrands studied showed an exponential loss of weight with time and a decrease in thermal decomposition as a function of temperature.

On the basis of the characteristics analysed, three firebrands groups have been identified in relation to spotting: heavy firebrands with ability to sustain flames, which would be efficient firebrands for long-distance spotting (pine cones); light firebrands with high surfaceto-volume ratio, which would be effective for short-distance spotting (leaves and thin barks) and light firebrands with low surface-to-volume ratio which would be efficient for short and, occasionally, long-distance spotting (all the other types of firebands).

Fire spotting results from a complex interplay between the numbers of firebrands produced, firebrand dispersal distances, ignition probabilities of the recipient fuel class, and the spatial arrangement of fuel types at the landscape scale. The number of firebrands produced by each fuel type and the probability of ignition may have compensating effects on spotting behaviour; greater numbers of lesssuccessful firebrands may produce the same pattern as fewer, more-successful ones (Hargrove et al. 2000).

Therefore, no strict recommendations could be derived from the results obtained in this study. Nevertheless, these results provide complementary information for potential spotting analysis in forest and fuel management plans and community wildfire protection strategies. Spotting potential, combined with forest structure data and fuel modelling, would improve fire hazard assessment (Fernandes 2009).

In future works, the results presented in this paper could be used as inputs for models describing the capability of firebrands to be carried up in the rising convection column or their capability to ignite secondary fires.

Acknowledgements This research was funded by the European Commission, Directorate General XII for Science, Research and Development, IV Environment and Climate Framework Research and Development Programme SALTUS ENV98-CT98-0701. We sincerely acknowledge the critical reviews of two anonymous referees who helped improve an earlier version of the manuscript.

\section{References}

Albini FA (1979) Spot fire distance from burning trees: a predictive model. Intermountain forest and range experiment station. USDA For. Serv., Gen. Tech. Rep. INT-56, Missoula, MT. p 75

Albini FA (1981) Spot fire distance from isolated sourcesextensions of a predictive model. Intermountain forest and range experiment station. USDA For. Serv., Research Note INT-309, Ogden, Utah. p 10 
Albini FA (1983) Potential spotting distance from wind-driven surface fires. Intermountain forest and range experiment station. USDA For. Serv., Gen. Tech. Rep. INT-309, Ogden, Utah. p 27

Alessio G, Peñuelas J, Lusia J, Ogaya R, Estiarte M, De Lillis M (2008) Influence of water and terpenes on flammability in some dominant Mediterranean species. Int J Wildland Fire 17:274-286

Anthenien RA, Tse SD, Fernandez-Pello AC (2006) On the trajectories of embers initially elevated or lofted by small scale ground fire plumes in high winds. Fire Saf J 41:349-363

Delabraze P and Valette JC (1974) Inflammabilité et combustibilité de la végétation méditerranéenne forestière méditerranéenne. Rev. Forest. Fr. No. Special. pp 171-177

Ellis PF (2000) The aerodynamic and combustion characteristics of eucalypt bark-a firebrand study. Ph.D. thesis, Australian National University, Canberra, Australia

Elvira L and Hernando C (1989) Inflamabilidad y energía de las especies de sotobosque, Monografía INIA no. 68, Madrid. 99 pp

Fernandes PM (2009) Combining forest structure data and fuel modelling to classify fire hazard in Portugal. Ann For Sci 66:415-419

Fonda RW (2001) Burning characteristics of needles from eight pine species. For Sci 47:390-396

Fonda RW, Varner JM (2004) Burning characteristics of cones from eight pine species. Northwest Sci 78(4):322-333

Fonda RW, Bellanger LA, Burley LL (1998) Burning characteristics of western conifer needles. Northwest Sci 72:1-9

Ganteaume A, Lampin C, Guijarro M, Hernando C, Jappiot M, PérezGorostiaga P, Vega-Hidalgo JA, Fonturbel T (2009) Spot fires. Fuel bed flammability and ignition capability of firebrands. Int $\mathrm{J}$ Wildland Fire 18:951-969

Gardner RH, Romme WH, Turner MG (1999) Predicting forest fire effects at landscape scales. In: Mladenoff DJ, Baker WL (eds) Spatial modelling of forest landscape change: approaches and applications. Cambridge University Press, Cambridge, pp 163-185

Hargrove WW, Gardner RH, Turner MG, Romme WH, Despain DG (2000) Simulating fire patterns in heterogeneous landscapes. Ecol Model 135(2-3):243-236

Hernando C, Moro C and Valette JC (1994) Flammability parameters and calorific values of Erica arborea and Arbutus unedo. In: Proceedings of the 2nd International Conference on Forest Fire Research, vol. I, 21-24 November 1994, Coimbra, Portugal. pp. 481-490

Himoto K and Tanaka T (2005) Transport of disk-shaped firebrands in a turbulent boundary layer. In: Proceedings of the 8th International Fire Safety Science Symposium. pp 433-444

Johnson RA, Wichern DW (1982) Applied multivariate statistical analysis. Prentice-Hall, New Jersey, 800

JRC (2009) EFFIS, Fire History. Available at: http://effis.jrc.ec. europa.eu/fire-history. Accessed 4 May 2009

Kane JM, Varner JM, Kevin HJ (2008) The burning characteristics of southeastern oaks: discriminating fire facilitators from fire impeders. For Ecol Manag 256:2039-2045

Liodakis S and Kakardakis $\mathrm{T}$ (2006) Measuring the particle flammability of forest species from wildland/urban interface
(WUI) near Athens by thermal analysis. First International Symposium on Environment Identities and Mediterranean Area (ISEIM) 2006 Conference (July 10-13, France). pp 24-28

Manzello SL, Cleary TG, Shields JR, Yang JC (2006a) Ignition of mulch and grasses by firebrands in wildland-urban interface fires. Int J Wildland Fire 15:427-431

Manzello SL, Cleary TG, Shields JR, Yang JC (2006b) On the ignition of fuel beds by firebrands. Fire Mater 30:77-87

Manzello SL, Maranghides A, Mell WE (2007) Firebrand generation from burning vegetation. Int J Wildland Fire 16:458-462

Manzello SL, Cleary TG, Shields JR, Maranghides A, Mell W, Yang JC (2008) Experimental investigation of firebrands: generation and ignition of fuel beds. Fire Saf J 43:226-233

McArthur AG (1967) Fire behaviour in eucalypt forest. Comm. of Australia For. and Timber Bur. Leaflet no. 107

Montgomery KR, Cheo PC (1971) Effect of leaf thickness on ignitibility. For Sci 17:475-478

Mutch RW (1970) Wildland fires and ecosystems - a hypothesis. Ecology 51:1046-1051

Núñez-Regueira L, Rodríguez Añón JA, Proupín CJ (1996) Calorific values and flammability of forest species in Galicia. Coastal and hillside zones. Biosource Technol 57:283-289

Ormeño E, Céspedes B, Sánchez IA, Velasco-García A, Moreno JM, Fernandez C, Baldy V (2009) The relationship between terpenes and flammability of leaf litter. For Ecol Manag 257:471-482

Pérez-Gorostiaga P, Vega JA, Fontúrbel MT, Guijarro M, Hernando C, Díez C, Martínez E, Lampin-Cabaret C, Blanc P and Colin PY (2002) Capability of ignition of some forest firebrands. In: Viegas DX (Ed.), Proceedings of IV International Conference on Forest Fire Research. 2002 Wildland Fire Safety Summit, Luso, Portugal, 18-23 November 2002. Millpress Scientific Publications, Rotterdam, the Netherlands (CD-ROM)

Pyne JS, Andrews PL, Laven RD (1996) Introduction to wildland fire. Wiley, New York, $769 \mathrm{p}$

Quézel P and Médail F (2003) Ecologie et biogeographie des forêts du bassin méditerranéen. Elsevier, Amsterdam. 592 p

SALTUS (2001) Fire spotting: mechanism analysis and modelling. EU Project ENV98-CT98-0701. Final report 'Probabilistic model'

Tarifa C.S., del Notario P.P., and Moreno F.G., 1967. Transport and combustion of fire brands. Final report of Grants FG-SP-114 and FG-SP-146, vol 2, Instituto Nacional de Técnica Aeroespacial Esteban Terradas, Madrid, Spain

Valette JC (1988) Inflammabilité, teneur en eau et turgescence relative de quatre espèces forestières méditerranéennes. In: Documents of the Seminar on Methods and Equipment for the Prevention of Forest Fire. ICONA, MAPA (ed.), Madrid, Spain. pp 98-107

Waterman TE, Takata AN (1969) Laboratory study of ignition of host materials by firebrands. Project J6142-OCD Work Unit 2539A. IIT Research Institute, Chicago

Woycheese JP, Pagni PJ, Liepmann D (1999) Brand propagation from large-scale fires. J Fire Prot Eng 10(2):32-44 